\title{
Quasi-Solid-State Hybrid Electrolytes for Electrochemical Hydrogen Gas Sensor
}

\author{
Sang-Hyung Kim ${ }^{1}$, Dong-Kwan Han ${ }^{1}$, SeungBo Hong ${ }^{1}$, Bo Ra Jeong ${ }^{1}$, Bok-Seong Park², Sang-Do Han ${ }^{3}$, \\ and Dong-Won Kim ${ }^{1, *}$ \\ ${ }^{1}$ Department of Chemical Engineering, Hanyang University, Seungdong-Gu, Seoul 04763, Republic of Korea \\ ${ }^{2}$ Engineering \& Technology, Sin Myung ENTEC Co., Ltd., Geumjeong-gu, Busan 46241, Republic of Korea \\ ${ }^{3} R \& D$ Center, ShinWoo Electronics Co., Ltd., Anyang-si, Gyeinggi-do 13936, Republic of Korea
}

\begin{abstract}
The quasi-solid-state hybrid electrolytes were synthesized by chemical cross-linking reaction of methacrylate-functionalized $\mathrm{SiO}_{2}\left(\mathrm{MA}-\mathrm{SiO}_{2}\right)$ and tetra (ethylene glycol) diacrylate in aqueous electrolyte. A quasi-solid-state electrolyte synthesized by 6 wt.\% MA-SiO 2 exhibited a high ionic conductivity of $177 \mathrm{mS} \mathrm{cm}^{-1}$ at room temperature. The electrochemical $\mathrm{H}_{2}$ sensor assembled with quasi-solid-state electrolyte showed relatively fast response and high sensitivity for hydrogen gas at ambient temperature, and exhibited better durability and stability than the liquid electrolyte-based sensor. The simple construction of the sensor and its sensing characteristics make the quasi-solid-state hydrogen sensor promising for practical application.
\end{abstract}

Keywords : Quasi-Solid-State Electrolyte, Hybrid Electrolyte, Electrochemical Sensor, Hydrogen Sensor, Ionic Conductivity

Received : 18 February 2019, Accepted : 11 April 2019

\section{Introduction}

As the renewable energy sources, fuel cells have been received much attention in transportation and stationary power generation [1-3]. Fuel cell is an electrochemical powering device that converts the chemical energy directly into the electrical energy by using hydrogen gas as a fuel. Hydrogen gas is being also widely used in many chemical processes and other industrial applications including aerospace, energy, medical and biomass processing [4-6]. However, the use of hydrogen may raise many safety concerns, and thus the detection of potentially hazardous hydrogen is receiving increased attention. In this respect, the development of the hydrogen sensors has been an important research topic in the field of process control and hydrogen detection for the sake of safety. In view of their application, the sensors should fulfill the requirements such as high sensitivity, low

*E-mail address: dongwonkim@hanyang.ac.kr

DOI: https://doi.org/10.33961/jecst.2019.03405

This is an open-access article distributed under the terms of the Creative Commons Attribution Non-Commercial License (http://creativecommons.org/licenses/by-nc/4.0) Attribution Non-Commercial License (http://creativecommons.org/licenses/by-nc/4.0)
which permits unrestricted non-commercial use, distribution, and reproduction in any which permits unrestricted non-commercial use, distrib
medium, provided the original work is properly cited. cost, long-term stability, high reliability, simple construction and easy operation. Further, the ambient temperature operation is an important criterion to achieve safe and reliable performance [7,8]. For this purpose, the electrochemical gas sensors have been widely used because of their high sensitivity, simplicity, low power consumption, easy operation and low cost compared to other types of sensors [9-13]. The electrochemical gas sensors are gas detectors that measure the concentration of a target gas by oxidizing or reducing the target gas at a sensing (working) electrode and measuring the resulting current. The electrochemical hydrogen sensor typically consists of proton-conducting liquid electrolyte and three electrodes (working, reference and counter electrodes) [14-18]. Unfortunately, the electrochemical sensors employing liquid electrolyte suffer from some drawbacks such as limited stability and durability, which are mainly attributed to the leakage and evaporation of the electrolyte. These problems could be overcome by replacing the liquid electrolyte by solid electrolyte. Compared to liquid electrolyte, solid electrolyte can be used in the form of thin film or pellet without any separator, which permits the fabrication of com- 


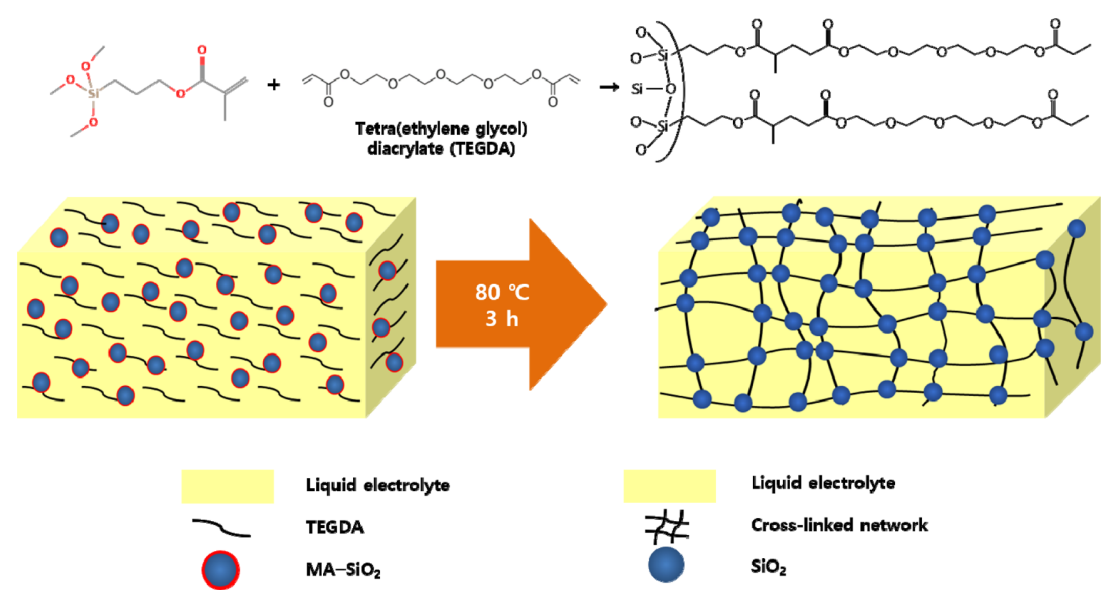

Fig. 1. Schematic illustration for synthesis of quasi-solid-state hybrid electrolyte using $\mathrm{MA}-\mathrm{SiO}_{2}$ particles and TEGDA at $80^{\circ} \mathrm{C}$.

pact device without electrolyte leakage and avoids deterioration of the sensing property. However, the main disadvantage of solid electrolytes is that they exhibit low ionic conductivities at room temperature, which precludes their practical applications in the electrochemical sensors operating at ambient conditions.

In this study, we prepared the highly conductive quasi-solid-state hybrid electrolytes by chemical cross-linking reaction of reactive $\mathrm{SiO}_{2}$ particles and tetra (ethylene glycol) diacrylate (TEGDA) in aqueous electrolyte. As the reactive $\mathrm{SiO}_{2}$ particles, we synthesized mesoporous $\mathrm{SiO}_{2}$ particles containing methacrylate groups on their surface to induce the free-radical reaction with TEGDA [19]. The methacrylate-functionalized $\mathrm{SiO}_{2}\left(\mathrm{MA}-\mathrm{SiO}_{2}\right)$ particles dispersed in aqueous electrolyte reacted with TEGDA, resulting in the formation of a three-dimensional network, as schematically demonstrated in Fig. 1. The electrochemical hydrogen sensor was fabricated by employing an optimized quasi-solid-state hybrid electrolyte and Pt-based working electrode. The $\mathrm{H}_{2}$ sensing performance was then evaluated and compared with that obtained in the electrochemical gas sensor assembled with sulfuric acid.

\section{Experimental}

\subsection{Synthesis of mesoporous $\mathrm{MA}^{\mathrm{A}} \mathrm{SiO}_{2}$ particles}

Mesoporous $\mathrm{MA}-\mathrm{SiO}_{2}$ particles were synthesized, as reported in our previous work [19]. Cetyltrimeth- ylammonium bromide $(0.4 \mathrm{~g})$ and L-lysine $(0.045 \mathrm{~g})$ were added to $140 \mathrm{ml}$ of a mixture of water/octane (10:1 by volume), and the solution was stirred at $70^{\circ} \mathrm{C}$ in a three-necked flask reactor. Styrene $(3.3 \mathrm{~g})$, tetraorthosilicate $(4.0 \mathrm{~g})$ and azobis(2-methylpropionamide) dihydrochloride ( 0.14$)$ were added into the reactor, and the mixture was stirred for $20 \mathrm{~h}$ at $70^{\circ} \mathrm{C}$ under a nitrogen atmosphere. After the reaction, the resulting solution was centrifuged and washed with ethanol. Polystyrene template was removed by heating at $550^{\circ} \mathrm{C}$ for $10 \mathrm{~h}$ to obtain mesoporous $\mathrm{SiO}_{2}$ nanoparticles. Surface modification of mesoporous $\mathrm{SiO}_{2}$ particles was carried out by using 3-methacryloxypropyltrimethoxy silane (MEMO, Evonik). Silica particles $(0.5 \mathrm{~g})$ was dispersed in methanol via ultrasonication for $30 \mathrm{~min}$, and $10.3 \mathrm{mmol} \mathrm{L}^{-1}$ of MEMO was added into the solution. The mixture was stirred for $1 \mathrm{~h}$ in order to induce surface functionalization with methacrylate groups. The resulting solution was centrifuged and washed with methanol several times. Mesoporous $\mathrm{MA}-\mathrm{SiO}_{2}$ particles were finally obtained as white powder after vacuum drying at $70^{\circ} \mathrm{C}$ for $12 \mathrm{~h}$.

\subsection{Synthesis of quasi-solid-state hybrid electrolyte}

TEGDA and benzoyl peroxide (BPO) was purchased from Sigma-Aldrich, and used as a cross-linking agent and a thermal radical initiator, respectively. Proper amount of TEGDA (10.0 wt.\%) and BPO $(0.2 \mathrm{wt} . \%)$ were dissolved in sulfuric acid $(3.0 \mathrm{M}$ $\mathrm{H}_{2} \mathrm{SO}_{4}$ ). Different amounts of $\mathrm{MA}-\mathrm{SiO}_{2}$ particles 
$(2.0,4.0,6.0,8.0 \mathrm{wt} . \%)$ were added into the electrolyte solution in order to control the degree of crosslinking during free-radical reaction. The quasi-solidstate hybrid electrolyte was then obtained by heating the precursor solution in $80^{\circ} \mathrm{C}$ oven for $3 \mathrm{~h}$ to induce the chemical cross-linking reaction between MA$\mathrm{SiO}_{2}$ particles and TEGDA, as presented in Fig. 1.

\subsection{Sensor fabrication}

The electrochemical sensor consists of the three planar electrodes, which were patterned on poly(tetrafluoroethylene) (PTFE) surface, as presented in Fig. 2(a). Both carbon reference electrode (RE) and Pt counter electrode (CE) were faced each other on the bottom side, and the Pt working electrode (WE) supported on porous carbon was patterned on the top side. The precursor solution containing $\mathrm{MA}-\mathrm{SiO}_{2}$ particles, TEGDA and BPO in $\mathrm{H}_{2} \mathrm{SO}_{4}$ electrolyte was cast by doctor blade on the bottom electrode. The sensor was then fabricated by sealing the bottom electrode and the top electrode together. The assembled sensor was placed at $80^{\circ}$ for $3 \mathrm{~h}$ to induce in-situ chemical cross-linking reaction and thus convert the precursor electrolyte solution to cross-linked quasi-solid-state electrolyte. After thermal curing, the quasi-solid-state electrochemical $\mathrm{H}_{2}$ sensor was finally obtained. The thickness of quasisolid-state hybrid electrolyte was measured to be about $2 \mathrm{~mm}$.

\subsection{Characterization and measurements}

The morphologies of the mesoporous $\mathrm{MA}-\mathrm{SiO}_{2}$ particles were examined using FE-SEM (JEOL JSM6330F) and TEM (JEOL JEM-2010). BET surface area of the mesoporous $\mathrm{MA}-\mathrm{SiO}_{2}$ particles was measured by a nitrogen adsorption-desorption method using a 3 Flex Surface Characterization Analyzer (Micromeritics). FT-IR spectra were obtained using a Magna IR 760 spectrometer in the range of 500-2,000 $\mathrm{cm}^{-1}$ with $\mathrm{KBr}$ powder-pressed pellets. The $\mathrm{pH}$ values of $3.0 \mathrm{M} \mathrm{H}_{2} \mathrm{SO}_{4}$ aqueous electrolyte and quasi-solid-state electrolyte were measured by using pH meter (2AA312, Xylem Analytics). AC impedance measurements of the blocking cells with stainless-steel (SS) electrodes were performed using an impedance analyzer (IM6, Zahner Electrik) to measure the ionic conductivity [20-22]. AC impedance spectrum of the SS/ electrolyte/SS cell in Fig. 2(b) consists of a spike
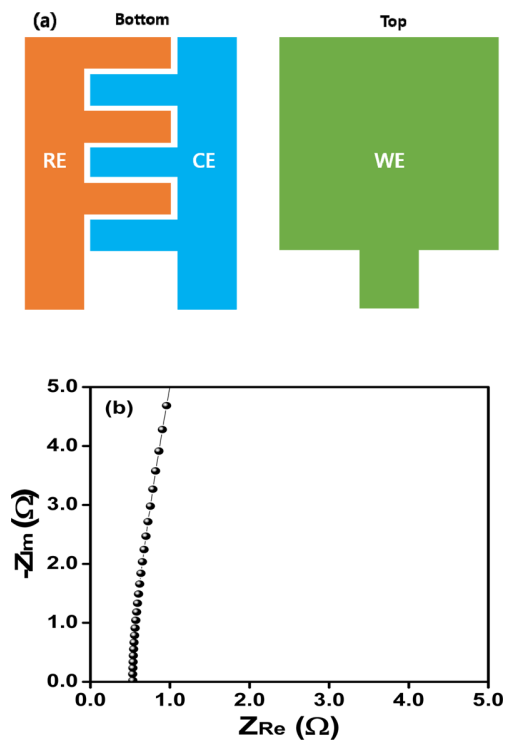

Fig. 2. (a) Electrode pattern consisted of three planar electrodes (working, reference and counter electrodes) in the electrochemical sensor. (b) AC impedance spectrum of the SS/electrolyte/SS cell for measuring the ionic conductivity at $25^{\circ} \mathrm{C}$.

displaced from the origin, which represents a resistor in series with a capacitor. The intercept on the real axis (X-axis) gave the resistance of the quasi-solid-state electrolyte, and the ionic conductivity could be calculated from its thickness and surface area. Cyclic voltammetry $(\mathrm{CV})$ of the electrochemical sensor with three-electrode configuration was performed in the potential range of -0.8 to $0.8 \mathrm{~V}$ vs. carbon reference electrode at a scan rate of $1 \mathrm{mV} \mathrm{s}^{-1}$ using a CHI660D electrochemical workstation. During CV experiments, constant flow of $\mathrm{H}_{2}$ gas (100 ppm $\mathrm{H}_{2}$ in nitrogen) was supplied to the working electrode. The electrochemical response of the sensor was evaluated using the same hydrogen gas (100 ppm $\mathrm{H}_{2}$ in nitrogen). The sensor was connected to Bio-Logic SP-300 potentiostat. The gas source was fed toward the working electrode using a mass flow controller. Current response of the electrochemical sensor was reported in chronoamperometric mode [23]. All the measurements were carried out at room temperature and common relative humidity of $40-50 \%$. In order to investigate the electrochemical behaviour of the electrochemical sensors with different electrolytes, the electrochemical impedance spectroscopy (EIS) were performed using Zahner Electrik IM6 impedance analyzer in the fre- 
quency range of $10 \mathrm{mHz}$ to $1 \mathrm{MHz}$ at an amplitude of $10 \mathrm{mV}$ before and after testing sensor performance.

\section{Results and Discussion}

FE-SEM image of the mesoporous $\mathrm{MA}-\mathrm{SiO}_{2}$ particles is presented in Fig. 3(a). The $\mathrm{MA}-\mathrm{SiO}_{2}$ particles have spherical shape with an average diameter of around $30 \mathrm{~nm}$. From the TEM image shown in Fig. 3 (b), it is found that that the mesoporous $\mathrm{MA}-\mathrm{SiO}_{2}$ particles have inner-pore channels that can provide pathways for $\mathrm{H}^{+}$ions to move through the mesoporous $\mathrm{SiO}_{2}$ particles. The BET surface area and pore volume of the $\mathrm{MA}-\mathrm{SiO}_{2}$ particles were measured to be $292.3 \mathrm{~m}^{2} \mathrm{~g}^{-1}$ and $1.14 \mathrm{~cm}^{3} \mathrm{~g}^{-1}$, respectively.

The $\mathrm{MA}-\mathrm{SiO}_{2}$ particles have reactive $\mathrm{C}=\mathrm{C}$ double bonds on their surface, and thus they can serve as inorganic cross-linking sites through free radical reaction with TEGDA in the aqueous electrolyte. In order to confirm the chemical cross-linking reaction between
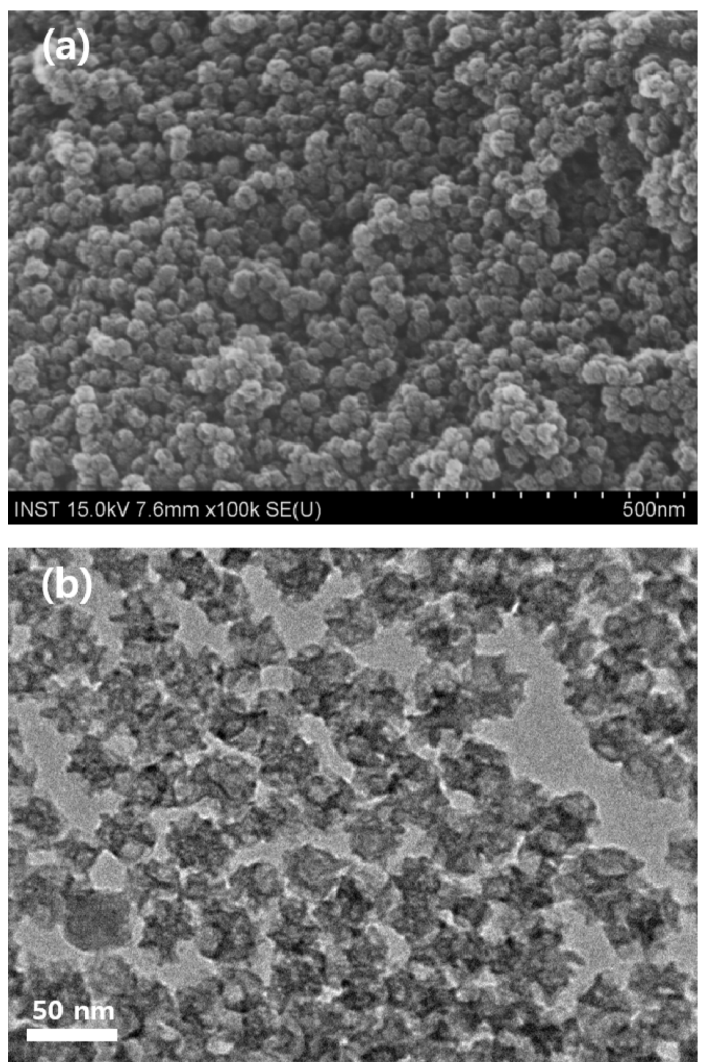

Fig. 3. (a) FE-SEM and (b) TEM images of the MA-SiO particles. mesoporous $\mathrm{MA}-\mathrm{SiO}_{2}$ particles and TEGDA, FT-IR spectra were analyzed before and after thermal crosslinking reaction. The FT-IR spectrum of $\mathrm{MA}-\mathrm{SiO}_{2}$ particles in Fig. 4(a) showed symmetrical stretching vibration of siloxane ( $\mathrm{Si}-\mathrm{O}-\mathrm{Si}$ ) at $766 \mathrm{~cm}^{-1}$ and asymmetrical stretching vibrations at 1190 and $1082 \mathrm{~cm}^{-1}$. The spectrum also exhibited a small peak at $1636 \mathrm{~cm}^{-1}$, which is a characteristic peak of $\mathrm{C}=\mathrm{C}$ double bond in the methacrylate group on the surface of $\mathrm{MA}-\mathrm{SiO}_{2}$ particles [24,25], indicating the $\mathrm{MA}-\mathrm{SiO}_{2}$ particles have reactive groups to permit free-radical reaction. Fig. 4(b) presents the FT-IR spectrum of the mixture of $\mathrm{MA}-\mathrm{SiO}_{2}$ particles and TEGDA before thermal cross-linking reaction. In addition to peak of $\mathrm{C}=\mathrm{C}$ double bond in the $\mathrm{MA}-\mathrm{SiO}_{2}$ particles, the peak corresponding to $\mathrm{C}=\mathrm{C}$ double bonds in TEGDA could be also observed at $1618 \mathrm{~cm}^{-1}$. The FT-IR spectrum of the quasi-solid-state hybrid electrolyte obtained after thermal cross-linking reaction revealed that the peaks corresponding to $\mathrm{C}=\mathrm{C}$ double bonds in the $\mathrm{MA}-\mathrm{SiO}_{2}$ particles $\left(1636 \mathrm{~cm}^{-1}\right)$ and TEGDA $\left(1618 \mathrm{~cm}^{-1}\right)$ disappeared after thermal cross-linking, as shown in Fig. 4(c). From these results, it was confirmed that methacrylate groups on the surface of $\mathrm{MA}-\mathrm{SiO}_{2}$ particles reacted with TEGDA through free radical reaction to form the three-dimensional cross-linked network, as demonstrated in Fig. 1.

Fig. 5(a) presents photographs of the cross-linked hybrid electrolytes cured by different amounts of $\mathrm{MA}-\mathrm{SiO}_{2}$ particles. After cross-linking reaction using $\mathrm{MA}-\mathrm{SiO}_{2}$ particles and TEGDA, the electrolyte

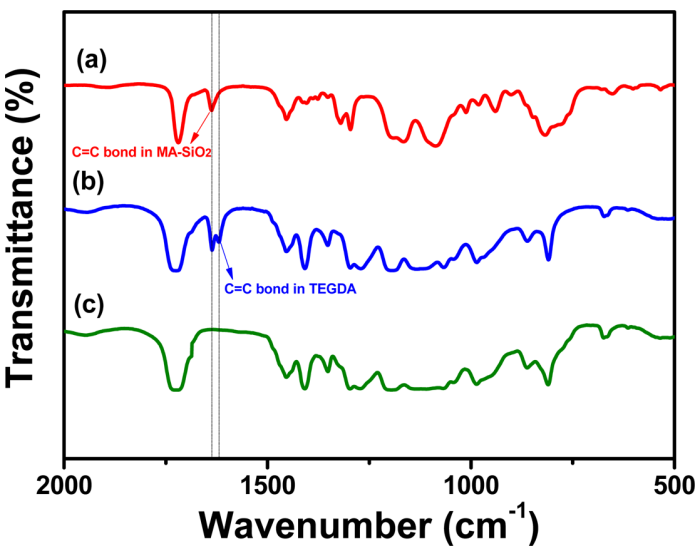

Fig. 4. FT-IR spectra of (a) $\mathrm{MA}-\mathrm{SiO}_{2}$ particles, (b) mixture of $\mathrm{MA}-\mathrm{SiO}_{2}$ particles and TEGDA and (c) cross-linked quasi-solid-state hybrid electrolyte. 

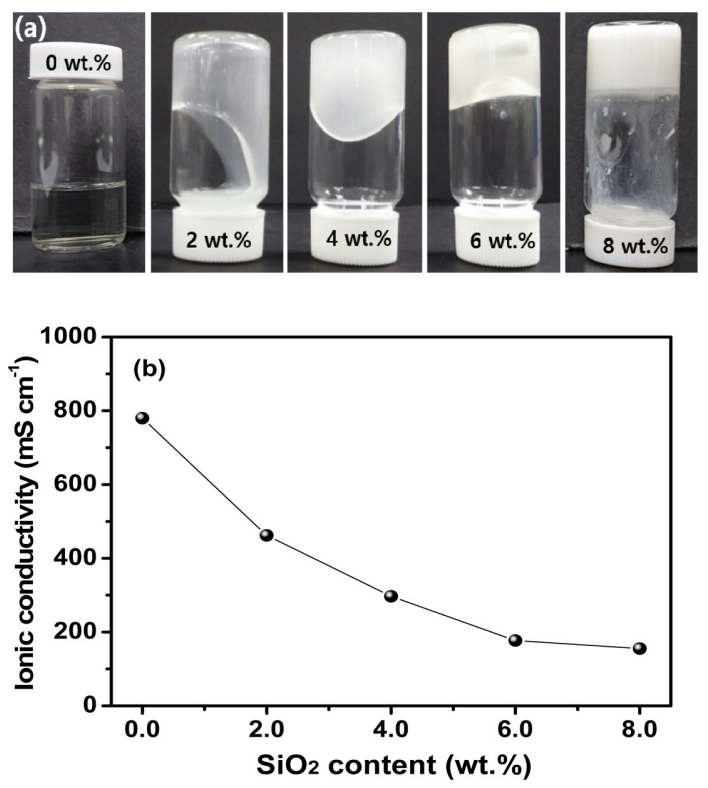

Fig. 5. (a) Photographs of liquid electrolyte and quasisolid-state hybrid electrolytes cured with different amounts of $\mathrm{MA}-\mathrm{SiO}_{2}$ particles and (b) ionic conductivities of quasisolid-state hybrid electrolytes as a function of content of $\mathrm{MA}-\mathrm{SiO}_{2}$ particles.

became highly viscous gel and finally non-fluidic due to the formation of three-dimensional cross-linked networks. It should be noted that the complete solidification without fluidity was not occurred when the $\mathrm{MA}-\mathrm{SiO}_{2}$ content was less than 6 wt. $\%$, which is attributed to low degree of cross-linking at low MA$\mathrm{SiO}_{2}$ content. This result suggests that the content of the $\mathrm{MA}-\mathrm{SiO}_{2}$ particles should be higher than $6 \mathrm{wt} . \%$ in order to prepare the dimensionally stable quasisolid-state electrolyte. Fig. 5(b) shows the ionic conductivities of the quasi-solid-state hybrid electrolytes as a function of $\mathrm{MA}-\mathrm{SiO}_{2}$ content at room temperature. For comparison, the ionic conductivity of the liquid electrolyte is also shown in the figure. As shown, the ionic conductivity of the quasi-solid-state electrolyte was decreased with increasing $\mathrm{MA}-\mathrm{SiO}_{2}$ content. The cross-linking reaction causes an increase in the resistance for ion migration due to the formation of three-dimensional networks, which results in a decrease of the ionic conductivity. For the electrolyte systems under study, the optimum MA$\mathrm{SiO}_{2}$ content was determined to be 6 wt. $\%$ when considering both ionic conductivity and dimensional stability. Accordingly, the quasi-solid-state hybrid

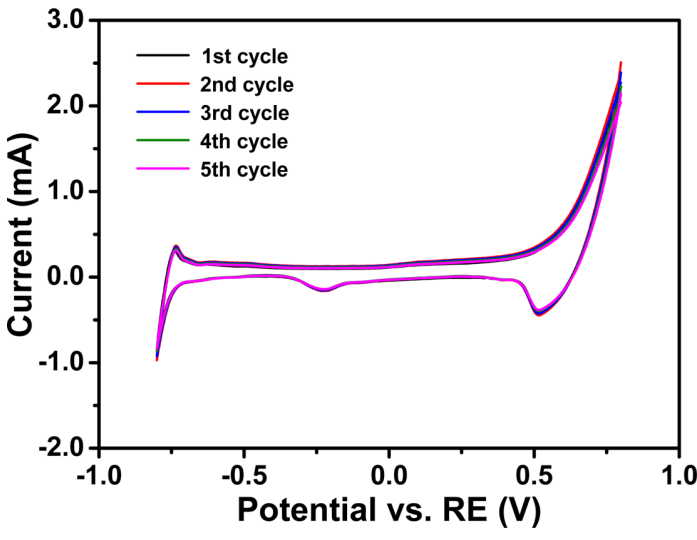

Fig. 6. Cyclic voltammograms of the electrochemical sensor with carbon reference electrode in $3.0 \mathrm{M} \mathrm{H}_{2} \mathrm{SO}_{4}$ aqueous electrolyte at a scan rate of $1 \mathrm{mV} \mathrm{s}^{-1}$.

electrolyte synthesized by 6 wt.\% $\mathrm{MA}-\mathrm{SiO}_{2}$ was used to in assembling the electrochemical hydrogen sensor. The ionic conductivity of the optimized electrolyte was $177 \mathrm{mS} \mathrm{cm}^{-1}$ at room temperature, which is a sufficiently high ionic conductivity for sensor applications.

The electrochemical sensor was assembled using a carbon as a reference electrode. To confirm the capability of carbon as a quasi-reference electrode, we performed cyclic voltammetry of the electrochemical sensor with carbon reference electrode in $3.0 \mathrm{M}$ $\mathrm{H}_{2} \mathrm{SO}_{4}$ aqueous electrolyte and observed the potential shift as a function of cycle. Fig. 6 presents CVs of the electrochemical sensor as a function of cycle, which were obtained in the presence of $\mathrm{H}_{2}$ gas. The anodic peak corresponding to the hydrogen oxidation is observed around $-0.74 \mathrm{~V}$ and the cathodic peak for oxygen reduction appeared at $0.51 \mathrm{~V}$. During the subsequent 5 cycles, the CVs show very stable currents without any signs of drifting or shifting of the peak potential. This result indicates that the carbon quasireference electrode exhibits a notable stability and reliability with low potential drift in the aqueous electrolyte. Lee et al. also demonstrated that the porous carbon electrode could be used as reliable quasi-reference electrode in the acid aqueous electrolyte [26].

The electrochemical performance of the $\mathrm{H}_{2}$ sensor was examined using amperometric measurements by sequentially exposing the sensor to 100 ppm hydrogen in nitrogen and then going to stop of gas flow. 

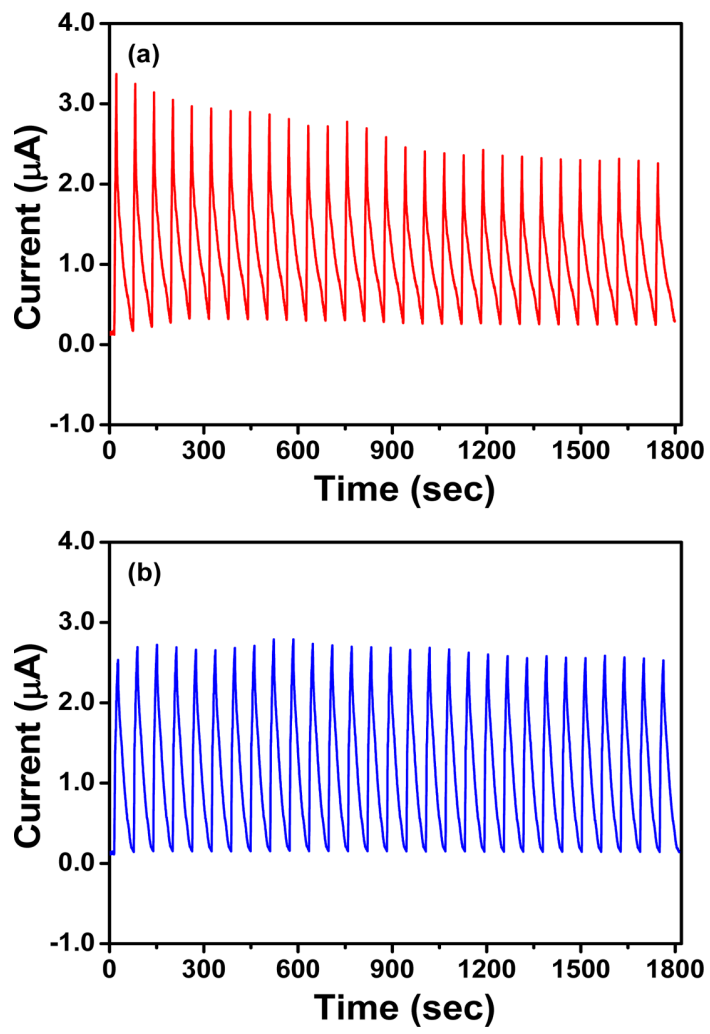

Fig. 7. Electrochemical response of the electrochemical $\mathrm{H}_{2}$ sensor upon exposure to $100 \mathrm{ppm} \mathrm{H}_{2}$. Sensor was assembled with (a) sulfuric acid electrolyte and (b) quasisolid-state hybrid electrolyte cured by 6.0 wt.\% $\mathrm{MA}-\mathrm{SiO}_{2}$ particles.

Fig. 7 shows the responses of the sensors assembled with liquid electrolyte and quasi-solid-state hybrid electrolyte to the repeated exposure of hydrogen gas. A fast response up to maximum current was observed within $12.0 \mathrm{sec}$. Upon stop of gas exposure, the current starts to decrease. It is well known that the electrochemical redox processes take place at the electrodes, i.e., oxidation at the working electrode and reduction at the counter electrode $[27,28]$.

$$
\begin{aligned}
& \mathrm{H}_{2}(\mathrm{~g}) \rightarrow 2 \mathrm{H}^{+}+2 \mathrm{e}^{-} \\
& 1 / 2 \mathrm{O}_{2}+2 \mathrm{H}^{+}+2 \mathrm{e}^{-} \rightarrow \mathrm{H}_{2} \mathrm{O}
\end{aligned}
$$

These redox reactions result in a flow of electrons as an external electrical current of the sensor, as depicted in Fig. 8. Both electrochemical reactions can only occur where the $\mathrm{H}^{+}$ions, electron (or electrode)

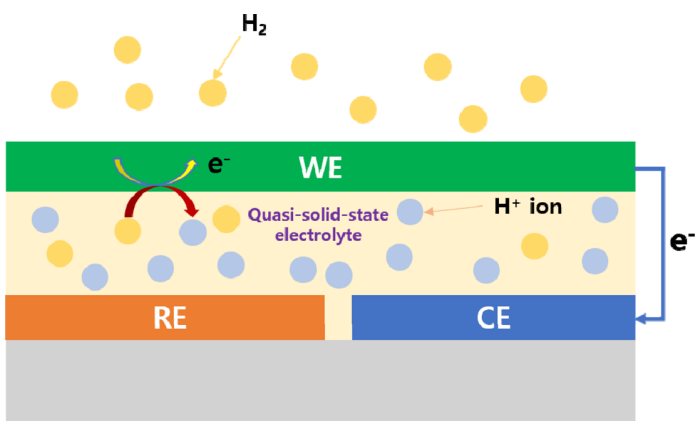

Fig. 8. Operating principle of the electrochemical $\mathrm{H}_{2}$ sensor.

and gas phases are all in contact. It is thought that the solubility and diffusion coefficient of $\mathrm{H}_{2}$ in the liquid electrolyte are larger than those in the quasi-solid-state electrolyte. The $\mathrm{pH}$ of $3.0 \mathrm{M} \mathrm{H}_{2} \mathrm{SO}_{4}$ solution (-0.68) is lower than that of quasi-solid-state electrolyte $(-0.54)$, indicating higher concentration of $\mathrm{H}^{+}$ions in the liquid electrolyte. Moreover, the ionic conductivity is much higher in the liquid electrolyte $\left(0.78 \mathrm{~S} \mathrm{~cm}^{-1}\right)$ than quasi-solid-state hybrid electrolyte $\left(0.18 \mathrm{~S} \mathrm{~cm}^{-1}\right)$. Accordingly, the sensor response was more rapid and the initial sensing current was higher in the liquid electrolyte-based sensor than sensor employing quasi-solid-state hybrid electrolyte. This result demonstrates that a type of electrolyte system plays an important role in determining the gas sensing performance of the electrochemical sensor $[29,30]$. It should be noted that the current response of the sensor with quasi-solid-state electrolyte was more stable during the repeated cycles, indicating the stable and reproducible redox processes at the electrodes. This result suggests that the hydrogen sensor employing a quasi-solid-state hybrid electrolyte can operate for much longer periods of time than the sensor assembled with liquid electrolyte.

In order to understand the electrochemical behavior of the electrochemical sensors with different electrolytes, their EIS analysis was performed. The resulting $\mathrm{AC}$ impedance spectra before and after amperometric measurements are shown in Fig. 9. The obtained spectra were analyzed using the equivalent circuit given in the inset of Fig. 9(a). In this circuit, $R_{E}$ is the electrolyte resistance, which is corresponding to the real axis intercept. $\mathrm{R}_{\mathrm{CT}}$ is the charge transfer resistance and $\mathrm{CPE}_{\mathrm{dl}}$ denotes the constant phase element of the double layer capacitance to reflect the depressed 

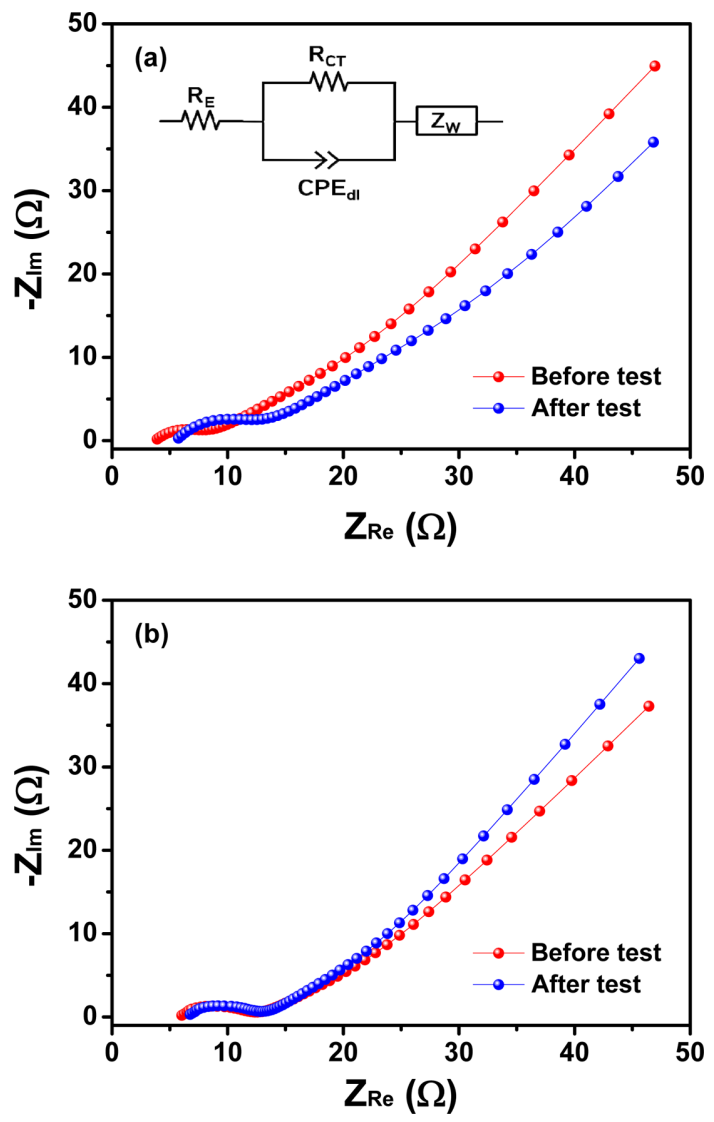

Fig. 9. AC impedance spectra of the electrochemical sensors assembled with (a) liquid electrolyte and (b) quasisolid-state hybrid electrolyte, which were obtained before and after sensor test. The equivalent circuit corresponding the spectra is given in the inset in (a).

semicircular shape, and $\mathrm{Z}_{\mathrm{w}}$ is Warburg impedance. In the sensor with liquid electrolyte, the values of $R_{E}$ and $R_{C T}$ increased after test. The increase of $R_{E}$ is mainly attributed to the gradual loss of liquid electrolyte during test, resulting from the evaporation of solvent under open $\mathrm{H}_{2}$ atmosphere condition. At the same time, the electrolyte depletion retarded the charge transfer reaction at the electrolyte-electrode interface, resulting in increase of $\mathrm{R}_{\mathrm{CT}}$. In contrast, the sensor with quasi-solid-state electrolyte exhibited the almost same values in $R_{E}$ and $R_{C T}$ before and after test. This result can be ascribed to the effective encapsulation of liquid electrolyte in the three-dimensional crosslinked networks as well as the good interfacial contact between quasi-solid-state electrolyte and elec- trodes, which resulted in enhanced stability of sensing performance, as presented in Fig. 7(b).

\section{Conclusions}

The quasi-solid-state hybrid electrolytes were synthesized using reactive methacrylate-functionalized $\mathrm{SiO}_{2}\left(\mathrm{MA}-\mathrm{SiO}_{2}\right)$ and tetra (ethylene glycol) diacrylate (TEGDA). A quasi-solid-state electrolyte synthesized with 6 wt. $\% \mathrm{MA}-\mathrm{SiO}_{2}$ and 10 wt.\% TEGDA formed the three-dimensional cross-linked networks without fluidity and exhibited a high ionic conductivity of $177 \mathrm{mS} \mathrm{cm}^{-1}$ at room temperature. The electrochemical $\mathrm{H}_{2}$ sensor was assembled with quasi-solidstate hybrid electrolyte, and its sensing performance was investigated. The quasi-solid-state electrochemical sensor showed relatively fast response and high sensitivity for hydrogen gas, and its sensing response was more stable than the sensor with liquid electrolyte. The simple, low cost, compact and robust construction of the electrochemical sensor and its high performance allowed the sensor to be used in various applications where hydrogen gas is utilized, especially fuel cell vehicles and stationary power generation systems.

\section{Acknowledgement}

This work was supported by the Technology Innovation Program funded by the Ministry of Trade, Industry and Energy (MOTIE, Korea) (10069215).

\section{References}

[1] M. Inci and O. Turksoy, J. Cleaner Production, 2019, 213, 1353-1370.

[2] T. Sadhasivam, K. Dhanabalan, S.-H. Roh, T.-H. Kim, K.-W. Park, S. Jung, M. D. Kurkuri, H.-Y. Jung, Int J Hydrogen Energy, 2017, 42(7), 4415-4433.

[3] H.-Y. Park, T.-Y. Jeon, K.-S. Lee, S. J. Yoo, Y.-E. Sung and J. H. Jang, J. Electrochem. Sci. Technol., 2016, 7(4), 269-276.

[4] B. H. Weiller, J. D. Barrie, K. A. Aitchison and P. D. Chaffee, Mater. Res. Soc. Symp. Proc. 1994, 360, 535540.

[5] R. Thimmappa, S. Shafi, S. Freunberger and M.O. Thotiyl, Int. J. Hydrogen Energy, 2016, 41(47), 2230522315.

[6] H. Han, S. Baik, B. Xu, J. Seo, S. Lee, S. Shin, J. Lee, J. H. Koo, Y. Mei, C. Pang and T. Lee, Adv. Funct. Mater., 2017, 27, 1701618. 
[7] M. Shi and F. C. Anson, J. Electroanal. Chem., 1996, 415(1-2), 41-46.

[8] B. Limoges, C. Degrand and P. Brossier, J. Electroanal. Chem., 1996, 402(1-2), 175-187.

[9] F. H. Garzon, R. Mukundan and E. L. Brosha, Solid State Ionics, 2000, 136-137, 633-638.

[10] S. Akbar and W. Weppner, J Mater. Sci., 2003, 38(23), 4639-4660.

[11] J. Zosel, G. Schiffel, F. Gerlach, K. Ahlborn, U. Sasum, V. Vashock and U. Guth, Solid State Ionics, 2006, 177(26-32), 2301-2304.

[12] G. Korotcenkov, S. D. Han and J. R. Stetter, Chem. Rev., 2009, 109(3), 1402-1433.

[13] T. Hubert, L. Boon-Brett, G. Black and U. Banach, Sens. Actuators B: Chem., 2011, 157(2), 329-352.

[14] Y. Dobrovolsky, L. Leonova and A. Vakulenko, Solid State Ionics, 1996, 86-88, 1017-1021.

[15] G. Korotcenkov, S. D. Han and J. R. Stetter, Chem. Rev., 2009, 109(3), 1402-1433.

[16] C. O. Park, J. W. Fergus, N. Miura, J. Park and A. Choi, Ionics, 2009, 15(3), 261-284.

[17] P. Pasierb and M. Rekas, J. Solid State Electrochem., 2009, 13(1), 3-25.

[18] J. F. M. Oudenhoven, W. Knoben and R. van Schaijk, Procedia Engineering, 2015, 120, 983-986.

[19] W.-K. Shin, J. Cho, A. G. Kannan, Y.-S. Lee and D.-W.
Kim, Sci. Rep., 2016, 6, 26332.

[20] D.-W. Kim, J.-M. Ko and J.-H. Chun, J. Power Sources, 2001, 93(1-2), 151-155.

[21] R. Miao, B. Liu, Z. Zhu, Y. Liu, J. Li, X. Wang and Q. Li, J. Power Sources, 2008, 184(2), 420-426.

[22] M. Li, X. Wang, Y. Wang, B. Chen, Y. Wu and R. Holze, RSC Adv, 2015, 5(65), 52382-52387.

[23] E. Jayanthi, N. Murugesan, A. S. Suneesh, C. Ramesh and S. anthonysamy, J. Electrochem. Sci., 2017, 164(8), H5210-H5217.

[24] Y.-S. Lee, J. H. Lee, J.-A. Choi, W. Y. Yoon and D.-W. Kim, Adv. Funct. Mater, 2013, 23(8), 1019-1027.

[25] W-.K. Shin, Y.-S. Lee and D.-W. Kim, J. Mater. Chem. A, 2014, 2(19), 6863-6869.

[26] J. Lee, N. Jackel, D. Kim, M. Widmaier, S. Sathyamoorthi, P. Srimuk, C. Kim, S. Fleischmann, M. Zeiger and V. Presser, Electrochim. Acta, 2016, 222, 1800-1805.

[27] M. Sakthivel and W. Weppner, Sens. Actuators B, 2006, 113(2), 998-1004.

[28] L. Leonova, L. Shmygleva, A. Ukshe, A. Levchenko, A. Chub and Y. Dobrovolsky, Sens. Actuators B: Chem., 2016, 230, 470-476.

[29] K. S. Kim and G. S. Chung, Sens. Actuators B: Chem., 2011, 157(2), 482-487.

[30] A. Sanger, A. Kumar, A. Kumar and R. Chandra, Sens. Actuators B: Chem., 2016, 234, 8-14. 